\title{
A Kinetic Study on Carburization of Fe by Using ${ }^{13} \mathrm{CO}$ Isotope Gas
}

\author{
Hyuk KIM, ${ }^{1)}$ Dong-Joon $\mathrm{MIN}^{21}$ and Sung-Mo JUNG ${ }^{3) *}$ \\ 1) Formerly Graduate Student with the Department of Metallurgical Engineering at Yonsei University, Currently Senior \\ Researcher for Hyundai Steel Co., Dangjin, 343-711 Korea. $\quad 2)$ Department of Metallurgical Engineering, Yonsei \\ University, Seoul, $120-749$ Korea. $\quad 3)$ Graduate Institute of Ferrous Technology, POSTECH, Pohang, $790-784$ Korea.
}

(Received on August 29, 2012; accepted on October 1, 2012)

\begin{abstract}
The current investigations were undertaken to clarify the kinetics of dissociation of $\mathrm{CO}$ gas into the molten iron and the effects of impurities in Fe. The interfacial reaction rate of $\mathrm{CO}$ on liquid iron at $1823 \mathrm{~K}$ was measured by means of ${ }^{13} \mathrm{CO}$ isotope exchange technique. Isotope exchange technique has been widely employed to evaluate the interfacial chemical reaction quantitatively. The experiments were carried out for the compositions of (0.002-3.31 mass\%) of carbon, (0.002-0.11 mass\%) of oxygen, (0.0026-0.1 mass\%) of sulfur and (0.0002-0.08 mass\%) of nitrogen employing quadruple mass spectrometry for product gas analysis. In the carburization of molten iron containing oxygen, sulfur, carbon and nitrogen by $\mathrm{CO}$, the interfacial reaction at gas-metal surface can be converted from adsorption limited control to dissociation limited reaction as the impurity concentrations of oxygen and sulfur increase. In particular, it was found that sulfur has greater influence on the conversion of rate limiting step of carburization reaction of molten iron.
\end{abstract}

KEY WORDS: carburization; adsorption; dissociation; rate limiting step; isotope exchange technique; quadruple mass spectrometry.

\section{Introduction}

Great efforts have been made to increase the productivity of blast furnace (BF) ironmaking processes due to the rapidly increased price of high grade iron ores and coking coals. The reactions occurring in $\mathrm{BF}$ ironmaking comprise preheating, indirect reduction, direct reduction and carburization from the top of the furnace down to the hearth. ${ }^{1)}$ Because the reduction rates in $\mathrm{BF}$ are much higher than that of carburization, it is required to improve the carburization reaction rate, which results in the accelerated formation of liquid $\mathrm{Fe}-\mathrm{C}$ melt followed by pronounced direct reduction rate at high temperatures. However, carburization of $\mathrm{Fe}$ at high temperatures has not received remarkable attention in the ironmaking process although the dissociation of $\mathrm{CO}$ molecule on liquid iron surface is an important reaction step in the scrap melting as well as BF ironmaking. Although the carburization of solid $\mathrm{Fe}$ has been the subject of numerous investigations, only a few studies on carburization of $\mathrm{Fe}-\mathrm{C}$ melt were carried out at high temperatures. ${ }^{2-4)}$

One of the earliest investigations were done by Parlee et al. ${ }^{5)}$ using a constant volume Sieverts's type apparatus. They concluded that the rate of adsorption and desorption of $\mathrm{CO}$ was primarily controlled by diffusion of oxygen in the metal. Schenk et al. ${ }^{6)}$ suggested that the liquid phase mass transfer were the rate-determining step with similar experimental equipment. King et $a l^{7)}$ have carried out the adsorption and desorption studies with only natural convection for stirring.

* Corresponding author: E-mail: smjung@postech.ac.kr DOI: http://dx.doi.org/10.2355/isijinternational.53.199
They concluded that the rate was controlled by liquid metal phase mass transfer. Solar and Guthrie ${ }^{8)}$ made Sieverts's type measurements for $\mathrm{CO}$ adsorption in stagnant state of iron and showed that the rate could be explained by diffusion coefficient of carbon in Fe. Suzuki and Mori ${ }^{9)}$ also did Sieverts's type experiments and refined the interpretation to include the mass transfer of carbon. Several investigations employed levitated drop methods to eliminate the effect of the crucible on the rate and they also found the rate was controlled by liquid phase mass transfer. ${ }^{10,11)}$ It was true in the work of Sasaki et al. ${ }^{3,4)}$ on carburization in $\mathrm{Ar}-\mathrm{CO}-\mathrm{H}_{2}$ mixture where the authors have suggested that the rate determining step in carburization reaction is diffusion in the molten $\mathrm{Fe}-\mathrm{C}$ phase. Ye et $a .^{12)}$ also reported that the carburization depends on the thickness of foil, and it means the diffusion in the liquid metal determines the rate.

Most of the previous researchers regarded that the diffusion in the molten or solid iron is the rate determining step without considering the interfacial chemical reaction rate. However, due to the isotope exchange technique, the interfacial reaction can be separated from the overall reaction since the isotope exchange reaction is not affected by liquid phase mass transfer. Recently, several investigators have used the isotope gases to clarify the reaction mechanisms of nitrogen dissolution into iron ${ }^{13,14)}$ and into $\mathrm{Fe}-\mathrm{Cr}$ alloys, ${ }^{15)}$ and $\mathrm{CO}_{2}$ reaction with iron ${ }^{16)}$ was investigated from a viewpoint of decarburization.

In the current study, an isotope gas was used to understand the chemical kinetics at the gas-metal interface. Labeled $\mathrm{CO}$ gas was used to discriminate ${ }^{13} \mathrm{C}$ from common carbon, ${ }^{12} \mathrm{C}$. With this labeled gas, the dissociation rate of 
$\mathrm{CO}$ was evaluated at $1823 \mathrm{~K}$. Moreover, the effects of other impurities in iron on the interfacial reaction were investigated since the surface active elements such as oxygen and sulfur in molten iron decrease the rates of interfacial chemical reactions of $\mathrm{CO}$ gas with molten iron by occupying reaction sites.

\section{Theoretical Background}

\subsection{Reaction Steps of Carburization of Fe with CO Gas}

The overall carburization of molten iron by $\mathrm{CO}$ gas can be represented by the following reaction:

$$
2 \mathrm{CO}(\mathrm{g})+\mathrm{Fe}(\mathrm{l}) \rightarrow \underline{\mathrm{C}}_{\text {in Fe}}+\mathrm{CO}_{2}
$$

The Reaction (1) can be divided into elementary steps as follows:

$$
\begin{array}{r}
2 \mathrm{CO}(\mathrm{g}) \rightarrow 2 \mathrm{CO}(\mathrm{ad}) \\
\mathrm{CO}(\mathrm{ad}) \rightarrow \mathrm{C}(\mathrm{ad})+\mathrm{O}(\mathrm{ad}) \\
\mathrm{C}(\mathrm{ad}) \rightarrow \underline{\mathrm{C}}_{\mathrm{in} \mathrm{Fe}} \\
\mathrm{O}(\mathrm{ad})+\mathrm{CO}(\mathrm{ad}) \rightarrow \mathrm{CO}_{2}(\mathrm{ad}) \\
\mathrm{CO}_{2}(\mathrm{ad}) \rightarrow \mathrm{CO}_{2}(\mathrm{~g})
\end{array}
$$

It is generally agreed that the carburization reaction between liquid $\mathrm{Fe}$ and $\mathrm{CO}$ gas consists of the five possible rate-determining steps:

a. Mass transfer of $\mathrm{CO}$ gas molecular onto the molten iron surface.

b. Dissociation of adsorbed $\mathrm{CO}$ into $\mathrm{C}$ and $\mathrm{O}$ adsorbed.

c. Diffusion of carbon from the surface to the bulk phase.

d. Removal of $\mathrm{O}$ on the surface by adsorbed $\mathrm{CO}$ as $\mathrm{CO}_{2}$.

e. Exhaust of reacted $\mathrm{CO}_{2}$.

These reactions proceed in series so that the overall rate constant, $k_{a}$ can be represented by:

$$
\frac{1}{k_{a}}=\frac{R T}{m_{\mathrm{CO}}}+\frac{1}{k_{f}}+\frac{R T}{D}+\frac{R T}{m_{\mathrm{CO}_{2}}}
$$

where

$$
\begin{aligned}
& k_{a}=\text { apparent rate constant } \\
& k_{f}=\text { forward rate constant } \\
& R=\text { ideal gas constant } \\
& T=\text { arbitrary temperature } \\
& m_{\mathrm{CO}}=\text { mass transfer coefficient of } \mathrm{CO} \text { gas } \\
& m_{\mathrm{CO}_{2}}=\text { mass transfer coefficient of } \mathrm{CO}_{2} \text { gas } \\
& D=\text { diffusion coefficient of carbon in molten iron }
\end{aligned}
$$

\subsection{Interfacial Chemical Reaction Rate}

Since all the experimental conditions were controlled so that the interfacial reaction could be the rate determining step, the apparent rate constant, $k_{a}$ can become the forward rate constant, $k_{f}$. However, the isotope exchange technique was employed to distinguish it from the dissociation reaction of normal $\mathrm{CO}$ by Eqs. (2) and (3):

$$
{ }^{13} \mathrm{CO}(\mathrm{g})={ }^{13} \mathrm{C}(\mathrm{ad})+\mathrm{O}(\mathrm{ad})
$$

Suppose that $k_{f}$ is the apparent forward rate constant and that $k_{r}$ is the reverse rate constant of the reaction for free surface, the overall reaction rate can be written as follows:

$$
-\frac{d n_{13} \mathrm{C}}{A d t}=k_{f} \cdot\left(1-\sum_{i} \theta_{i}\right) \cdot p_{{ }^{13} \mathrm{CO}}-k_{r} \cdot \theta_{{ }^{13} \mathrm{C}} \cdot \theta_{\mathrm{O}}
$$

where $\theta_{i}$ is the fraction of surface sites which are occupied by surface active element $i$ which can block the dissociation of $\mathrm{CO}$ by adsorption on the reaction site. $A$ is the surface area of reaction. $n$ and $p$ denote number of moles and partial pressure, respectively. Assuming that the reaction at the gasmetal interface is in equilibrium, the overall reaction rate should be zero:

$$
k_{f} \cdot\left(1-\sum_{i} \theta_{i}\right) \cdot p^{13} \mathrm{CO}=k_{r} \cdot \theta_{13} \mathrm{C} \cdot \theta_{\mathrm{O}}
$$

Because normal $\mathrm{CO}$ gas can be treated in the similar manner, Eq. (10) can be rewritten as follows:

$$
k_{f} \cdot\left(1-\sum_{i} \theta_{i}\right) \cdot p_{\mathrm{CO}}=k_{r} \cdot \theta_{\mathrm{C}} \cdot \theta_{\mathrm{O}}
$$

Equation (11) can be converted into the following equation and its substitution for the right hand side of Eq. (9) yields Eq. (13):

$$
\begin{array}{r}
k_{f} \cdot\left(1-\sum_{i} \theta_{i}\right) \cdot p_{\mathrm{CO}} \cdot \frac{1}{\theta_{\mathrm{C}}}=k_{r} \cdot \theta_{\mathrm{O}} \ldots . \\
-\frac{d n_{{ }^{13} \mathrm{CO}}}{A d t}=k_{f} \cdot\left(1-\sum_{i} \theta_{i}\right) \cdot\left(p_{{ }^{13} \mathrm{CO}}-p_{\mathrm{CO}} \cdot \frac{\theta_{{ }^{13} \mathrm{C}}}{\theta_{\mathrm{C}}}\right)
\end{array}
$$

If the reaction occurs in the condition of surface reaction rate control, the occupying probability of ${ }^{13} \mathrm{C}$ and $\mathrm{C}$ can be regarded as similar. And the concentration of ${ }^{13} \mathrm{C}$ and $\mathrm{C}$ are too dilute in this study, thus the value of $\theta_{{ }^{13} \mathrm{C}} / \theta_{\mathrm{C}}$ can be regarded to be unity. And the replacement of the mole of ${ }^{13} \mathrm{CO}$ with the diminution of $p^{{ }^{13} \mathrm{CO}}$ yields Eq. (14) considering the exposure of a volume of gas $V$ to an area of metal surface $A$ at temperature $T$ and $1 \mathrm{~atm}$ pressure:

$$
\frac{\bar{V}}{A R T} \cdot\left(-\frac{d p^{{ }^{13} \mathrm{CO}}}{d t}\right)=k_{f} \cdot\left(1-\sum_{i} \theta_{i}\right) \cdot\left(p_{{ }^{13} \mathrm{CO}}-p_{\mathrm{CO}}\right) .
$$

where $A\left(\mathrm{~cm}^{2}\right)$ is the surface area of molten metal, $\bar{V}\left(\mathrm{~cm}^{3} /\right.$ sec) is the volume flow rate, $T(\mathrm{~K})$ is the temperature of gas, $R\left(82.1 \mathrm{~cm}^{3} \mathrm{~atm} / \mathrm{Kmol}\right)$ is the gas constant. Integrating this expression from $t=0$ to $t=t$ with the initial condition, $p_{{ }^{13} \mathrm{CO}}=p_{{ }^{13} \mathrm{CO}}^{*}$ yields Eq. (15):

$$
k_{f} \cdot\left(1-\sum_{i} \theta_{i}\right)=-\frac{\bar{V}}{A R T} \cdot \ln \left(\frac{p_{{ }^{13} \mathrm{CO}}-p_{\mathrm{CO}}}{p_{{ }^{13} \mathrm{CO}}^{*}-p_{\mathrm{CO}}}\right) \ldots \ldots
$$

Since the partial pressure of each gas is proportional to the ion current of detected gas by quadruple mass spectrometry (QMS), the partial pressure of each gas can be replaced by its ion current:

$$
k_{f} \cdot\left(1-\sum_{i} \theta_{i}\right)=-\frac{\bar{V}}{A R T} \cdot \ln \left(\frac{I_{13} \mathrm{CO}-I_{\mathrm{CO}}}{I^{* 3} \mathrm{CO}-I_{\mathrm{CO}}}\right) \ldots \ldots
$$

For the sake of convenience in presenting the results, the left hand side of Eq. (16) can be replaced by the apparent rate constant of the symbol, $k_{a}$ i.e.:

$$
k_{a}=k_{f}\left(1-\sum_{i} \theta_{i}\right)
$$

where $k_{a}$ has the unit of mole $\cdot \mathrm{cm}^{-2} \cdot \mathrm{sec}^{-1} \cdot \mathrm{atm}^{-1}$. 


\section{Experimental}

\subsection{Materials Preparation}

Electrolytic iron and other compounds ( $\mathrm{FeS}, \mathrm{Fe}-\mathrm{C}$ alloy, Nitride, etc.) were pre-melted and the alloys were chemically analyzed by using LECO $\mathrm{C} / \mathrm{S}$ and N/O analyzer. The alloys compositions used in this study are shown in Table $\mathbf{1 .}$

High purity gases of Ar (99.9999\%), CO (99.5\%) and ${ }^{13} \mathrm{CO}(99.9 \%)$ were used in this study. Each gas was purified by passing through drierite $\left(\mathrm{CaSO}_{4}\right)$ and silica gel. In the case of $\mathrm{CO}$ gas, soda-lime was added to the columns to remove residual $\mathrm{CO}_{2}$ in gas. Total flow rate of gas mixture was set to be $400 \mathrm{~mL} / \mathrm{min}$ to eliminate the effect of gas phase mass transfer.

After passing through the columns, each gas was mixed in the mixing chamber filled with alumina balls to make the turbulence flow. Mixed gas was introduced onto the molten metal surface for carburization. Product gases were passed through a filter to remove some dust for protecting QMS. The apparatus is similar to a common analysis instrument, but has a short stream line to save expensive ${ }^{13} \mathrm{CO}$ gas and special care was taken of adsorption in the gas line or QMS due to high pressure of $\mathrm{CO}$ gas.

Table 1. Compositions of experimental specimens.

\begin{tabular}{lllll}
\hline No. & wt $\% \mathrm{C}$ & $\mathrm{wt} \% \mathrm{O}$ & $\mathrm{wt} \% \mathrm{~S}$ & $\mathrm{wt} \% \mathrm{~N}$ \\
\hline$\# 1$ & 0.0733 & 0.6170 & 0.0106 & 0.0821 \\
$\# 2$ & 0.0019 & 0.0563 & 0.0026 & 0.0003 \\
$\# 3$ & 0.8960 & 0.0020 & 0.0510 & 0.0046 \\
$\# 4$ & 0.1810 & 0.0094 & 0.0056 & 0.0084 \\
$\# 5$ & 3.3100 & 0.1084 & 0.0600 & 0.0010 \\
$\# 8$ & 0.1410 & 0.0120 & 0.0180 & 0.0060 \\
$\# 9$ & 0.0241 & 0.0424 & 0.0142 & 0.0020 \\
$\# 10$ & 0.0658 & 0.0065 & 0.0099 & 0.0115 \\
$\# 11$ & 0.4202 & 0.0080 & 0.0059 & 0.0041 \\
$\# 12$ & 0.0409 & 0.0111 & 0.0135 & 0.0500 \\
$\# 13$ & 0.0629 & 0.0066 & 0.0116 & 0.0077 \\
\hline
\end{tabular}

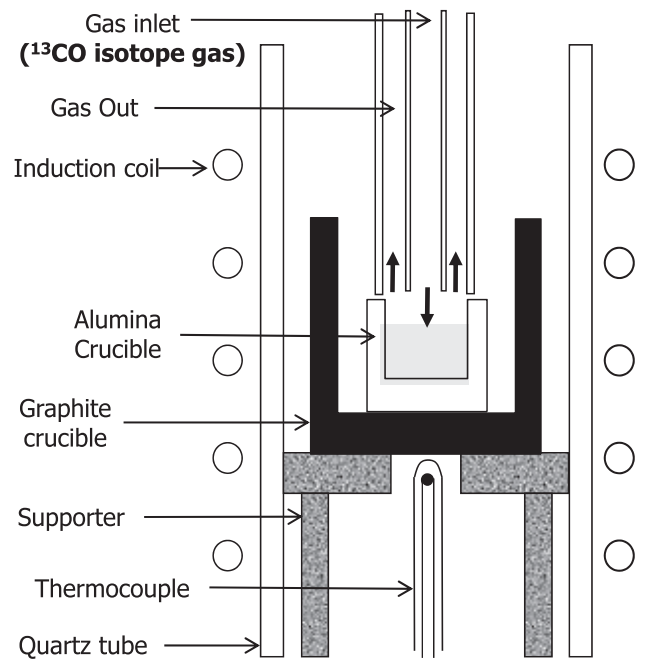

Fig. 1. Schematic diagram of experimental apparatus.

\subsection{Apparatus and Procedure}

Figure 1 shows the experimental apparatus employed in the present study. The temperature of induction furnace was controlled by PID within $\pm 2 \mathrm{~K}$. Because the induction furnace has a great advantage of high heating rate, the initial composition of the specimens can be maintained unchanged at high temperatures. Graphite was used as a heating susceptor to maintain a uniform temperature profile over the specimen. To prevent the side reaction by graphite, the quartz tube was filled with Ar gas of ultra high purity (purity: $99.9999 \%$ ) by passing it through the $\mathrm{Mg}$ turnings at 773 $\mathrm{K}$. The purity of the purged atmosphere was preliminarily checked by QMS. Dual cored alumina lance was used for supplying the reactive gas and for collecting the reaction product gas. A distance between the end of the lance and the crucible was minimized to prevent the leak of reaction gases.

After placing the specimens in the position, the furnace was completely purged with Ar gas. When the target temperature was reached, the gas mixture of $\mathrm{CO}$ and ${ }^{13} \mathrm{CO}$ was introduced into the specimen. The lance of exit gas was connected to QMS for monitoring the gas compositions. The preliminary test was done to examine the relevance of equipment to measure the rate constant. Similar experiments for carburization were performed in the temperature range of 1373 to $1773 \mathrm{~K}$. Figure 2 compared the preliminary data with other reference data. The preliminary experiment was done intentionally under the condition of the surface reaction. The rate from this study shows good agreement with the data measured by Fruehan ${ }^{19)}$ in the condition of interfacial reaction control, which indicates that the apparatus is accurate enough to measure the rate of ${ }^{13} \mathrm{CO}$ dissociation. Moreover, the data indicated that the carburization rate is limited by mixed control of gas phase mass transfer and/or interfacial reaction. Therefore, the gas flow rate was increased above the critical value in such a way that gas phase mass transfer could be excluded from the rate-limiting steps.

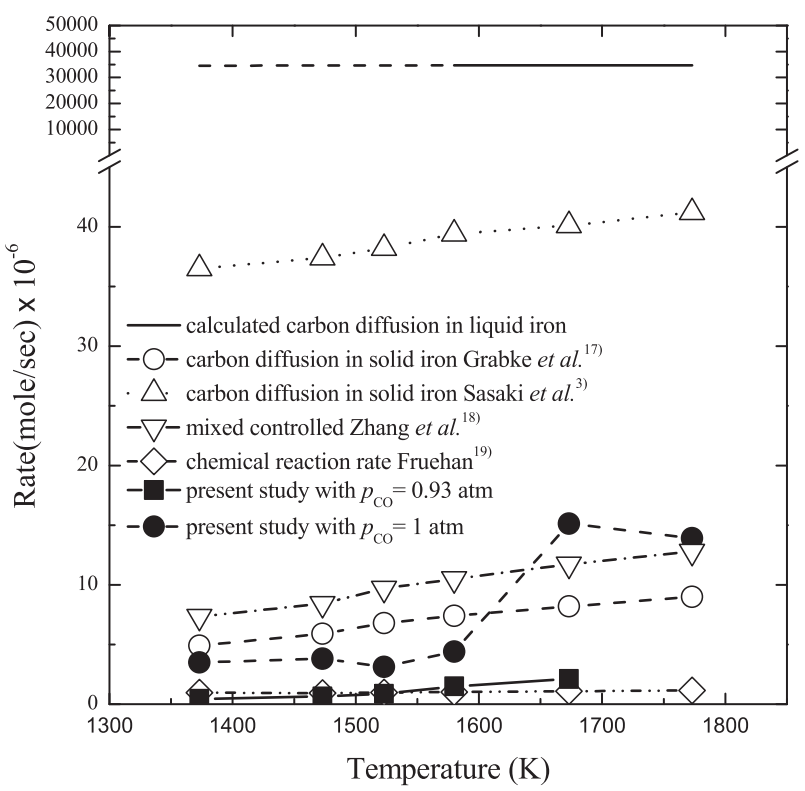

Fig. 2. Comparison of the rate of elementary step with the other reference data at $1373-1773 \mathrm{~K}$. 


\section{Results and Discussion}

\subsection{Compositional Change of Product Gases by QMS}

Figure 3 is the primary data of product gases in the reference state at $1823 \mathrm{~K}$. The ion current of each gas can be converted to gas concentrations because the ion current is proportional to the concentration. The steady changes of intensity of $\mathrm{CO},{ }^{13} \mathrm{CO}$ and $\mathrm{CO}_{2}$ gases after 600 seconds represent the quasi-chemical equilibrium of carburization reaction. Since the carbon deposition reaction occurred with current gas composition of $100 \% \mathrm{CO}$ at that temperature, it makes sense that $\mathrm{CO}_{2}$ gas was detected in spite of no input of $\mathrm{CO}_{2}$ gas. The reference condition was required to separate the initial and reacted $\mathrm{CO}_{2}$ gases. While the carburization reaction took place at the gas-metal surface, the carbon activity continued to increase. The increase of carbon activity in Fe might disturb the carburization as an obstacle for

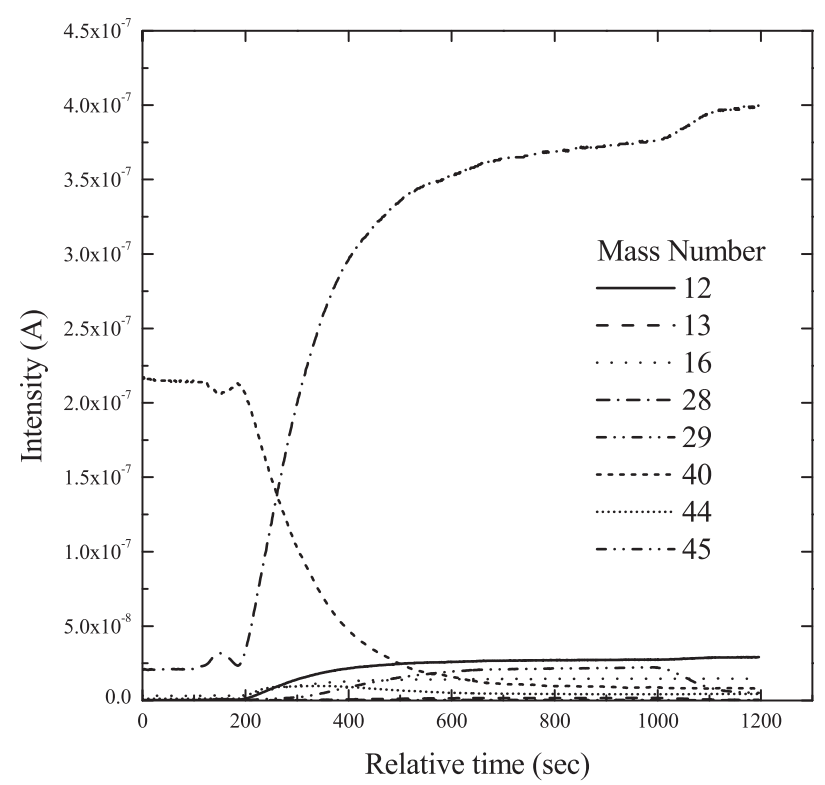

Fig. 3. Typical gas composition detected by quadruple mass spectrometer.

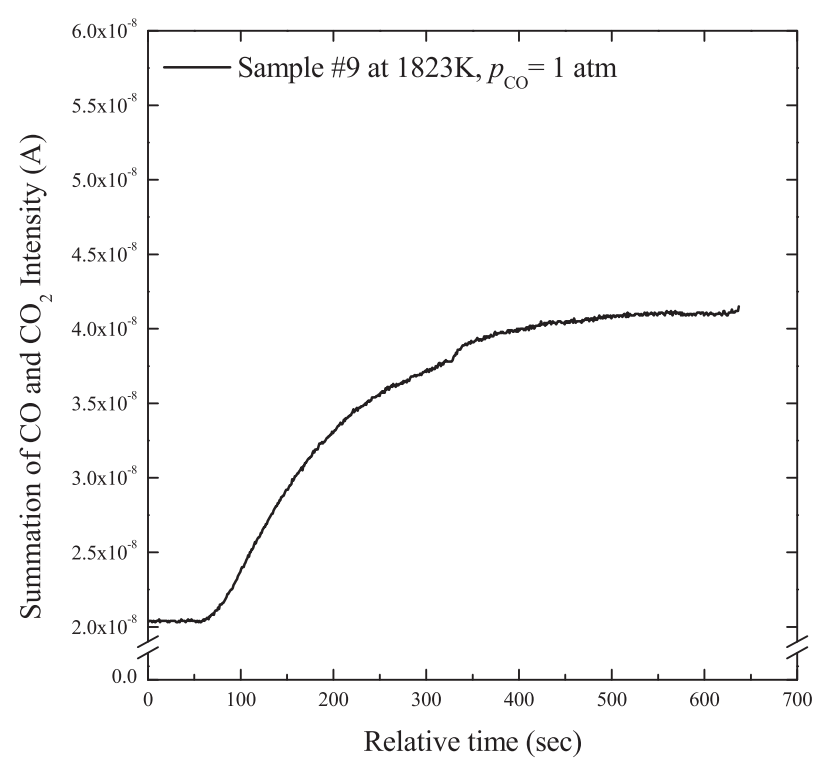

Fig. 4. Summation of $\mathrm{CO}$ and $\mathrm{CO}_{2}$ gas to determine if the carburization could begin. the experimental period.

As shown in Fig. 4, the summation of $\mathrm{CO}$ and $\mathrm{CO}_{2}$ compositions in the product gases reached some constant value. Accordingly, the possibility of reduction of the specimen due to its residual oxygen in Fe was ruled out with this composition of product gas in the reference state. The ion currents of gases by QMS showed linear relationships with the gas compositions, thus Eq. (15) for evaluating the rate constants can be converted into Eq. (16). In comparison with the ion current of reference gas, the change of ion current can be calculated, which results in evaluating the rate constant of carburization. Table 2 shows the apparent rate constant of each sample. Due to the limited control of iron compositions, the adsorption coefficient, $K_{\mathrm{i}}$ is required to evaluate the forward rate constant on the free surface.

\subsection{Effect of Oxygen on Carburization}

Several investigations have been undertaken to clarify the behavior of surface active elements such as oxygen, sulfur, nitrogen, and so on. ${ }^{20)}$ Figure 5 shows the effect of surface active elements on surface tension. The results in Fig. 5 indicate that oxygen and sulfur have the tendency to stabilize the metal surface by decreasing the surface tension. However, these elements would be a barrier of $\mathrm{CO}$ adsorption on the metal surface from a viewpoint of carburization. That is, the surface tension is closely related to the bonding

Table 2. Apparent rate constant of each sample.

\begin{tabular}{cc}
\hline No. & $k_{a}\left(\mathrm{moles} / \mathrm{cm}^{2} \cdot \mathrm{sec} \cdot \mathrm{atm}\right) \times 10^{6}$ \\
\hline$\# 1$ & 0.211 \\
$\# 2$ & 4.206 \\
$\# 3$ & 2.165 \\
$\# 4$ & 1.012 \\
$\# 5$ & 0.071 \\
$\# 8$ & 4.339 \\
$\# 9$ & 0.854 \\
$\# 10$ & 8.511 \\
$\# 11$ & 8.015 \\
$\# 12$ & 3.558 \\
$\# 13$ & 6.712 \\
\hline
\end{tabular}

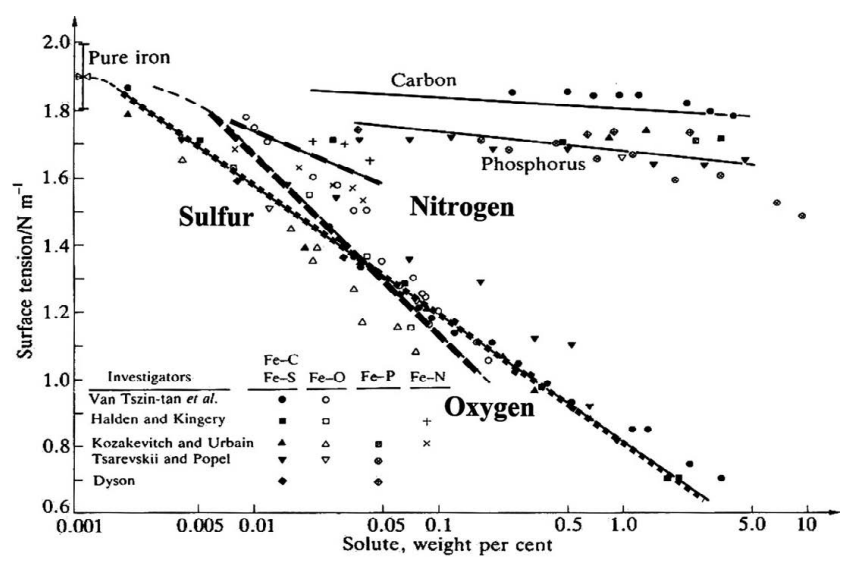

Fig. 5. Effect of various non-metals on the surface tension of liquid iron at $1823-1843 \mathrm{~K}^{20)}$ 
energy of each atom on the surface. According to the Gibbs surface theory, the element in the bulk liquid moves to the site on the surface to reduce the surface tension, which means the element moves to make itself more stable. In the case of sulfur in Fig. 5, the surface tension remarkably changes with increasing sulfur in liquid iron, which indicates most of sulfur is positioned on the surface. Of course the sulfur on the surface disturbs $\mathrm{CO}$ adsorption by decreasing the available vacant sites. Sain and Belton ${ }^{21)}$ have already estimated the adsorption coefficient with Langmuir adsorption isotherm under the assumption that the gas-metal reaction is controlled by the adsorption of gas on the surface. Let the filled site be $\theta$, then vacant site would be (1$\theta$ ) and the adsorption coefficient of element $i, K_{i}$ can be defined as follows:

$$
\begin{gathered}
i+\left(1-\theta_{i}\right) \rightarrow \theta_{i} \\
\frac{\theta_{i}}{\left(1-\theta_{i}\right) a_{i}}=K_{i}
\end{gathered}
$$

The ideal adsorption coefficient for oxygen, $K_{\mathrm{O}}$ is well known. Taking intermediate temperature into account, $K_{\mathrm{O}}$ can be represented by Eq. (20).

$$
\log K_{\mathrm{O}}=\frac{2910}{T}+0.47^{16)}
$$

The dissolved oxygen in $\mathrm{Fe}$ is in equilibrium with the adsorbed oxygen:

$$
\underline{\mathrm{O}}_{(\text {dissolved in } \mathrm{Fe})}=\mathrm{O}_{(\mathrm{ad})}
$$

where the standard states for the dissolved oxygen in the bulk liquid and for the adsorbed oxygen on the surface are with respect to $1 \mathrm{wt} \%$ in liquid iron and Raoultian standard state (i.e. full coverage of the surface sites by oxygen), respectively. The adsorption coefficient might be readily derived by combining Eq. (20) with the appropriate thermodynamic data, ${ }^{22)}$ yielding:

$$
\log K_{\mathrm{O}}^{\prime}=\frac{11370}{T}-4.09
$$

At $1823 \mathrm{~K}$ this gives a value of 140 for $K_{\mathrm{O}}^{\prime}$ with a reasonable uncertainty of $\pm 5 \% .{ }^{16)}$ With this result, the apparent rate constant can be calculated as follows:

$$
\frac{1}{k_{a}}=\frac{1}{k_{f}}+\frac{1}{k_{f}} \cdot K_{\mathrm{O}}^{\prime} a_{\mathrm{O}}
$$

Since oxygen was infinitely dilute in the Henrian region of molten iron, Eq. (23) yields:

$$
\frac{1}{k_{a}}=\frac{1}{k_{f}}+\frac{1}{k_{f}} \cdot K_{\mathrm{O}}^{\prime}[\mathrm{wt} \% \mathrm{O}]
$$

According to the similar procedure to that for deriving Eq. (24), the relationship between the apparent rate constant and adsorption coefficient can be derived in case the dissociation reaction, Eq. (3) is the rate limiting step of carburization. Starting with Eq. (19), the following relationships can be derived:

$$
k_{a}=k_{f}\left(1-\theta_{\mathrm{O}}\right)^{2}
$$

$$
\begin{gathered}
k_{a}=\frac{k_{f}}{\left(1+K_{\mathrm{O}}^{\prime}[\mathrm{wt} \% \mathrm{O}]\right)^{2}} \ldots \ldots . . \\
\frac{1}{\sqrt{k_{a}}}=\frac{1}{\sqrt{k_{f}}}+\frac{1}{\sqrt{k_{f}}} K_{\mathrm{O}}^{\prime}[\mathrm{wt} \% \mathrm{O}]
\end{gathered}
$$

Figure 6 shows the relationships between the apparent rate constant and oxygen content in the molten iron for the adsorption and dissociation limited step of carburization, respectively. In Fig. 6, it is believed that many scatters and the difference of forward rate constant between the adsorption and dissociation limited control is due to the effect of sulfur in the specimens. In Fig. 6(a), the forward rate constant for oxygen-free surface was evaluated to be $1.52 \times 10^{-5}$ mole $\cdot \mathrm{cm}^{-2} \cdot \mathrm{sec}^{-1} \cdot \mathrm{atm}^{-1}$ by extrapolation, whose value is in the similar order of magnitude to those reported previously. ${ }^{19)}$ And the forward rate constant of $6.52 \times 10^{-5}$ mole $\cdot \mathrm{cm}^{-2}$. $\mathrm{sec}^{-1} \cdot \mathrm{atm}^{-1}$ for the adsorption limited control is compared with that of $1.89 \times 10^{-5} \mathrm{~mole} \cdot \mathrm{cm}^{-2} \cdot \mathrm{sec}^{-1} \cdot \mathrm{atm}^{-1}$ for the dissociation limited control. This indicates that the carburization reaction of liquid iron containing carbon, oxygen, sul-

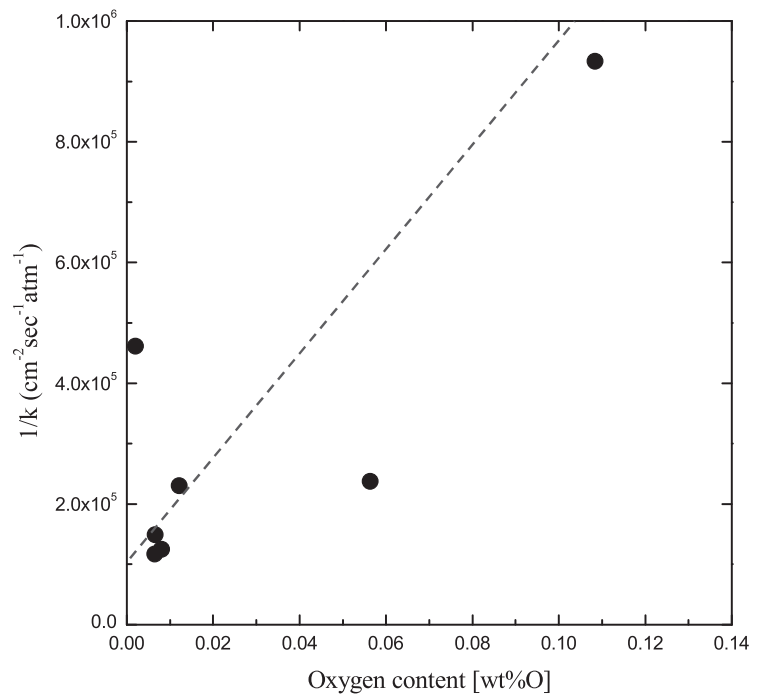

(a)

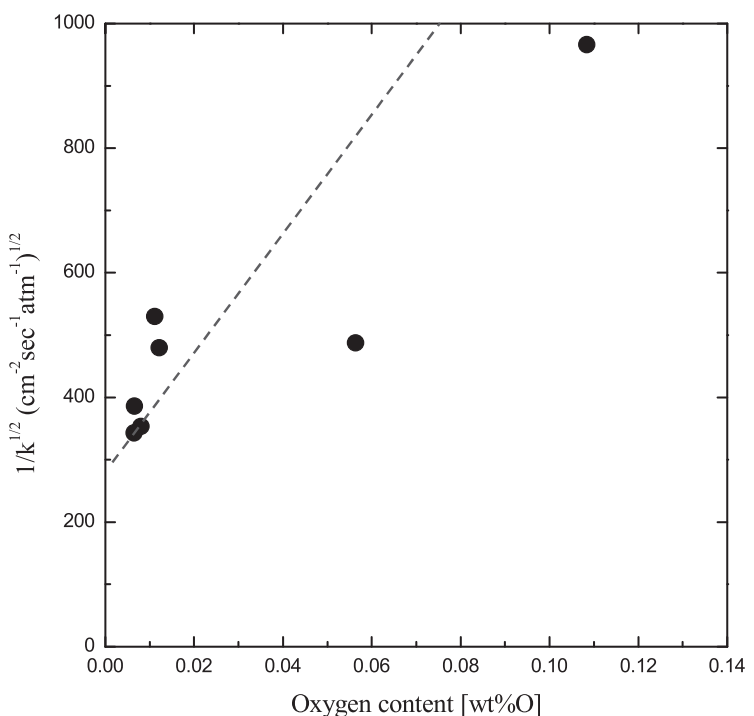

(b)

Fig. 6. Reciprocal of the apparent rate constant as a function of the oxygen content at $1823 \mathrm{~K}$. 
fur, carbon and nitrogen can be determined by the dissociation limited control. Considering the role of carbon for enhancing the activity of sulfur into account, ${ }^{23)}$ the current results about the dissociation limited control of carburization by $\mathrm{CO}$ indicates that the effect of sulfur on carburization is great, which will be discussed in the next session.

\subsection{Effect of Sulfur on Carburization}

As previously discussed, not only oxygen but also the other elements might affect the carburization reaction. As is similar to oxygen, let the filled site by sulfur be $\theta_{\mathrm{S}}$, then vacant site would be (1- $\left.\theta_{\mathrm{S}}\right)$ and the adsorption coefficient of element $\mathrm{S}, K_{\mathrm{S}}$ can be defined as follows:

$$
\begin{gathered}
\mathrm{S}+\left(1-\theta_{\mathrm{S}}\right) \rightarrow \theta_{\mathrm{S}} \\
\frac{\theta_{\mathrm{S}}}{\left(1-\theta_{\mathrm{S}}\right) a_{\mathrm{S}}}=K_{\mathrm{S}}
\end{gathered}
$$

where the standard state for the sulfur in the bulk liquid is with reference to $1 \mathrm{wt} \%$ in liquid iron.

$$
\frac{1}{k_{a}}=\frac{1}{k_{f}}+\frac{1}{k_{f}} \cdot K_{\mathrm{S}} a_{\mathrm{S}}
$$

The adsorption coefficient of sulfur has already been estimated by Mannion and Fruehan ${ }^{24)}$ and that its temperature dependence can be represented by Eq. (31):

$$
\log K_{\mathrm{S}}=\frac{3600}{T}+0.57^{24)}
$$

At $1823 \mathrm{~K}$ this gives a value of 350 for $K_{\mathrm{S}}$ with a reasonable uncertainty of $\pm 5 \%$. Figure 7 shows the reciprocal apparent rate constant as a function of sulfur activity in the molten iron for the adsorption and dissociation limited cases, respectively. There are lots of scatters as with the case of oxygen. In Fig. 7, the forward rate constant of $1.53 \times 10^{-5}$ mole $\cdot \mathrm{cm}^{-2} \cdot \mathrm{sec}^{-1} \cdot \mathrm{atm}^{-1}$ for the adsorption limited control is almost similar to that of $2.26 \times 10^{-5} \mathrm{~mole} \cdot \mathrm{cm}^{-2} \cdot \mathrm{sec}^{-1} \cdot \mathrm{atm}^{-1}$ for the dissociation limited control. It is believed that the smaller difference of forward rate constant in each limited control compared with the case of oxygen is ascribed to the effect of oxygen, which is weaker than that of sulfur. This indicates that the carburization reaction of liquid iron might be determined by either the adsorption or dissociation limited control.

\subsection{Effects of Oxygen and Sulfur on Carburization}

As already pointed out in Fig. 5, the oxygen and sulfur simultaneously affect the surface tension of the alloys as surface active element. Since both oxygen and sulfur affect the rate constants, the interfacial reaction should be described for two or more elements, i.e.:

$$
k_{a}=\frac{k_{f}}{1+\sum_{i} K_{i} a_{i}}
$$

In the case of oxygen and sulfur coexisting as impurities, Eq. (32) can be expressed by Eq. (33):

$$
k_{a}=\frac{k_{f}}{1+K_{\mathrm{O}} a_{\mathrm{O}}+K_{\mathrm{S}} a_{\mathrm{S}}}
$$

Using the evaluated forward rate constants for the cases of the adsorption and dissociation limited control, the relationships between the apparent rate constant and the activi-

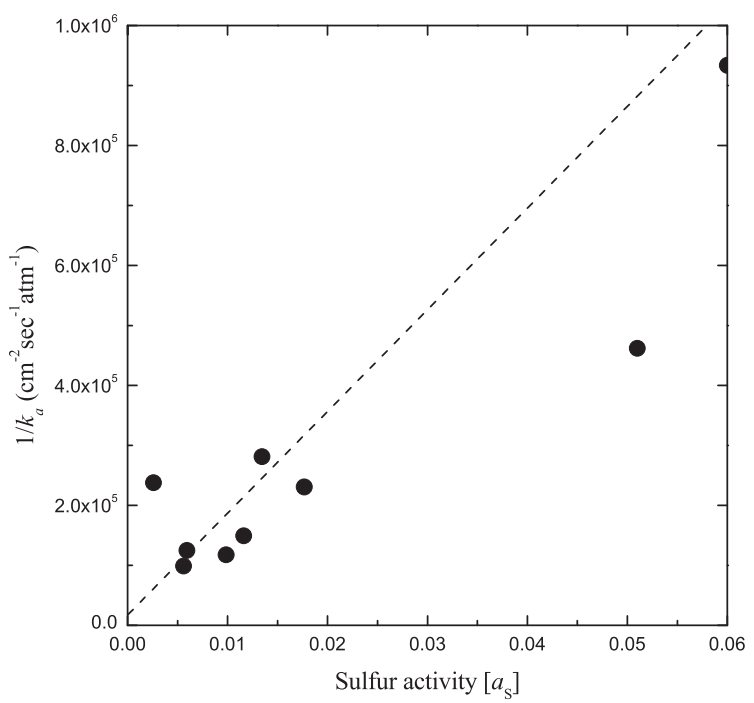

(a)

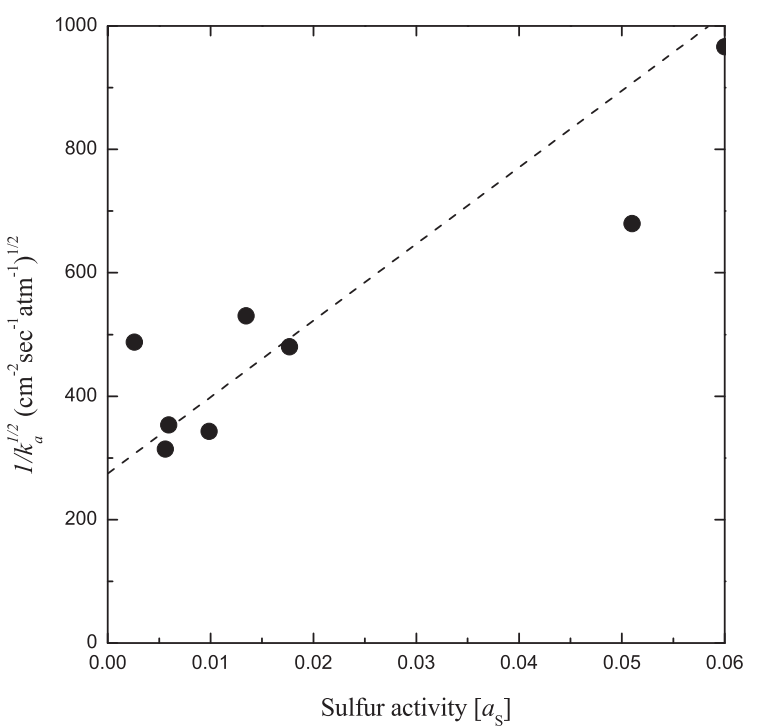

(b)

Fig. 7. Reciprocal of the apparent rate constant as a function of the sulfur activity at $1823 \mathrm{~K}$.

ties of oxygen and sulfur were derived as solid lines as shown in Fig. 8. And the measured data were plotted in the Fig. 8. In Fig. 8(a), it is clearly shown that the carburization reaction of the alloy where oxygen activity is higher than 0.02 is determined by mixed control of adsorption and dissociation, while the reaction is controlled by adsorption limited reaction for the composition where oxygen activity is less than 0.02 . Therefore, the apparent rate constant for the absorption limited control can be described by Eq. (33) in terms of forward rate constant.

On the other hand, in the case of sulfur, the carburization reaction is controlled by dissociation limited reaction over the composition of sulfur investigated. Accordingly, the apparent rate constant can be expressed by Eq. (34) in terms of sulfur-related parameters only. The means that the dissociation limited control strongly depend on the sulfur content rather than oxygen concentration. The tendency in Fig. 8 indicates that the rate limiting step can be changed depending on the contents of oxygen and sulfur in the alloys.

$$
k_{a}=\frac{k_{f}}{\left(1+K_{\mathrm{S}} a_{\mathrm{S}}\right)^{2}}
$$




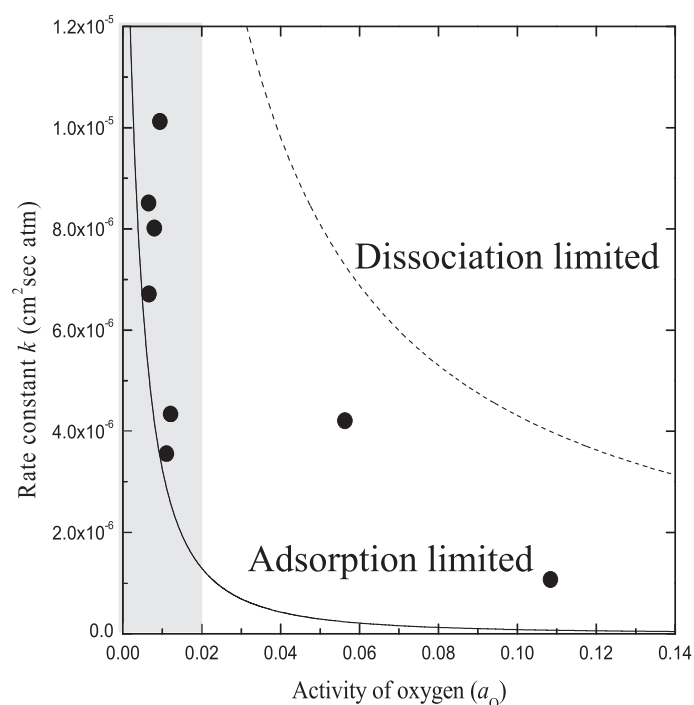

(a)

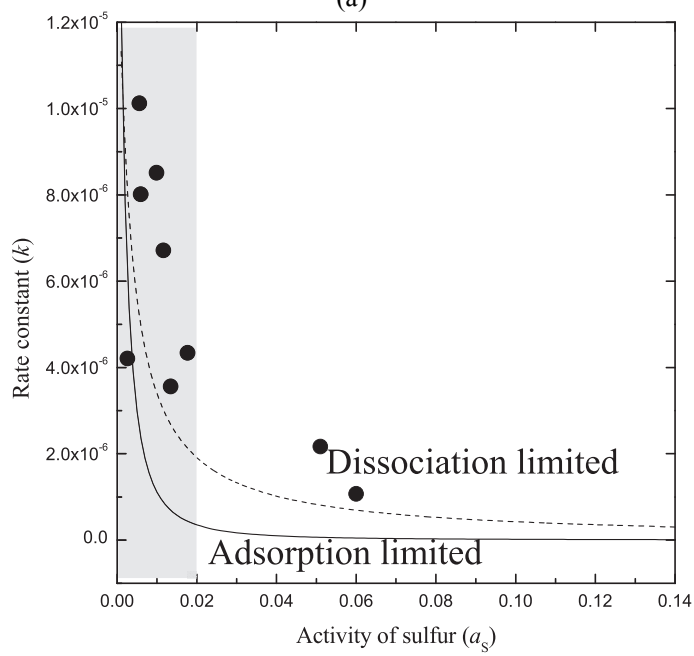

(b)

Fig. 8. Comparison of adsorption and dissociation limited reactions as a function of the activities of oxygen and sulfur at $1823 \mathrm{~K}$.

\subsection{Conversion of Rate Limiting Step by Composi- tional Change}

As high performance steels for automotive, construction, engineering steel, offshore, packaging and so on are required to develop and produce, in-depth research are strongly pursued for new steel grades having improved physical properties such as high strength, high toughness, good corrosion resistance, and good formability. To cope with the current requirement in new steel grades, the impurities in liquid iron produced by $\mathrm{BF}$ operation should be minimized.

Based on the results shown in Fig. 8, it was attempted that the carburization of Fe on the gas-metal surface can be visualized as shown in Fig. 9. That is, in case the apparent rate constant can be represented by Eq. (33) for the low impurities regions where the oxygen and sulfur activities are less than 0.02 , it was confirmed that the carburization reaction is determined by adsorption limited control. As shown in Fig. 9(a), it is believed that the adsorbed molecules are easy to dissociate into adsorbed atoms due to enough vacant sites around the adsorbed sites. This also indicates that the activation energy for the adsorption reaction of $\mathrm{CO}$ gas molecules on the vacant sites of the surface is larger than that for

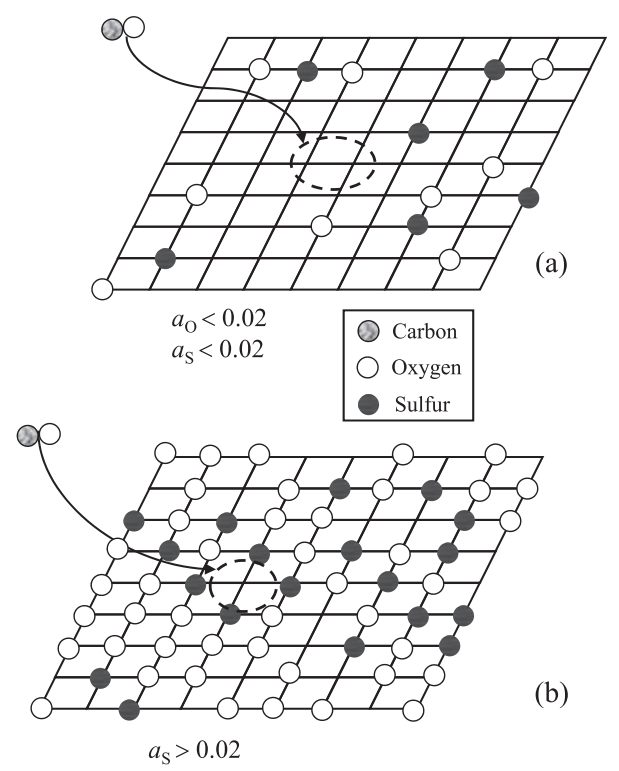

Fig. 9. Change of rate determining step with increasing the activities of oxygen and sulfur in the bulk phase at $1823 \mathrm{~K}$.

the dissociation reaction. Compared with this, when the liquid $\mathrm{Fe}$ contains high impurities where the sulfur activity is higher than 0.02 , the rate limiting step of the carburization reaction can be converted to dissociation reaction because it is difficult for the adsorbed molecules to dissociate into atoms due to fewer vacant sites around them. This also means that the activation energy for the adsorption reaction of $\mathrm{CO}$ gas molecules on the vacant sites of the surface is smaller than that for the dissociation reaction. In this case, even though the $\mathrm{CO}$ gas molecules are easily adsorbed onto the vacant sites of the metal surface, it is not easy to find vacant sites for dissociation. This might result in easy desorption of adsorbed $\mathrm{CO}$ molecules from the metal surface in molten iron containing high impurity.

\section{Conclusions}

The interfacial reaction of carburization was measured by quadruple mass spectrometry at $1823 \mathrm{~K}$ using ${ }^{13} \mathrm{CO}$ isotope gas. From the research, the following conclusions were obtained.

(1) The interfacial reaction of carburization of molten iron by $\mathrm{CO}$ was separated by employing the isotope exchange technique of ${ }^{13} \mathrm{CO}$ gas.

(2) The forward rate constant of carburization of molten iron for oxygen-free surface was evaluated to be $1.52 \times 10^{-5}$ mole $\cdot \mathrm{cm}^{-2} \cdot \mathrm{sec}^{-1} \cdot \mathrm{atm}^{-1}$ by extrapolation.

(3) Surface adsorption coefficients of oxygen and sulfur, $K_{\mathrm{O}}$ and $K_{\mathrm{S}}$ were applied to evaluate the forward rate constant. The apparent rate constant in the Henrian region was represented as follows considering the effect of sulfur on oxygen:

$$
k_{a}=\frac{k_{f}}{1+K_{\mathrm{O}}[\mathrm{wt} \% \mathrm{O}]+K_{\mathrm{S}}[\mathrm{wt} \% \mathrm{~S}]}
$$

(4) It was found that the carburization reaction is controlled by dissociation limited reaction over the composition of sulfur investigated. Accordingly, the apparent rate constant can be expressed in terms of sulfur-related parameters 
only. The means that the dissociation limited control strongly depend on the sulfur content rather than oxygen concentration:

$$
k_{a}=\frac{k_{f}}{\left(1+K_{\mathrm{S}} a_{\mathrm{S}}\right)^{2}}
$$

(5) In the carburization of molten iron containing oxygen, sulfur, carbon and nitrogen by $\mathrm{CO}$, the interfacial reaction at gas-metal surface is determined by adsorption or dissociation limited reaction depending on the impurities level. In particular, sulfur has strong influence on the conversion of rate limiting step of carburization reaction of molten iron.

\section{REFERENCES}

1) A. K. Viswas: Principles of Blast Furnace Ironmaking, SBA Pub., Calcutta, India, (1981), 8

2) R. J. Fruehan and S. Antolin: Metall. Trans. B, 18B (1987), 415.

3) Y. Sasaki, R. Asano and K. Ishii: ISIJ Int., 41 (2001), 209.

4) R. Asano, Y. Sasaki and K. Ishii: ISIJ Int., 42 (2002), 121.

5) N. A. Parlee, S. R. Seagle and R. Schuharann: Trans. TMS-AIME, 212 (1958), 132.

6) H. Schenk, E. Steinmetz and R. Thielmann: Arch Eisenhüttenwes., 44 (1973), 27
7) T. B. King, R. A. Karasev and P. Dastur: Heterogeneous Kinetics and Elevated Temperature, ed. by G. R. Belton and W. L. Worrell, Plenum Press, New York, (1970), 409.

8) M. Y. Solar and R. I. L. Guthrie: Metall. Trans., 3 (1972), 713.

9) K. Suzuki and K. Mori: Trans. Iron Steel Inst. Jpn., 17 (1977), 136.

10) P. A. Distin, G. D. Hallet and F. D. Richardson: JISI, 206 (1968), 821.

11) L. A. Baker, N. A. Warner and A. E. Jenkins: Trans. TMS-AIME, 239 (1967), 857.

12) X. Ye, H. Numata and S. Haruyama: J. Jpn Inst. Met., 49 (1985), 529.

13) M. Byrne and G. R. Belton: Metall. Trans. B, 14B (1983), 441.

14) P. C. Glaws and R. J. Fruehan: Metall. Trans. B, 16B (1985), 551.

15) P. C. Glaws and R. J. Fruehan: Metall. Trans. B, 17B (1986), 317.

16) A. Cramb and G. B. Belton: Metall. Trans. B, 12B (1981), 699.

17) H. J. Grabke, E. M. Muller-Lorenz and A. Schneider: ISIJ Int., 41 (2001), S1.

18) X. Zhang, R. Takahashi, T. Akiyama and J. Yagi: Tetsu-to-Hagané, 83 (1997), 13.

19) R. J. Fruenhan: Metall. Trans., 4 (1973), 2129.

20) B. C. Allen: Liquid Metals-Chemistry and Physics, ed. by S. Z. Beer, Marcel Dekker, New York, (1972), 171

21) D. R. Sain and Belton: Metall. Trans. B, 7 B (1976), 235.

22) J. F. Elliott, M. Gleiser and V. Ramakrishina: Thermochemistry for Steelmaking, vol. 2, Addison-Wesley Pub. Co., Reading, MA, (1963), 360.

23) F. Tsukihashi and R. J. Fruehan: Trans. Iron Steel Inst. Jpn., 27 (1987), 858

24) F. J. Mannion and R. J. Fruehan: Metall. Trans. B, 20B (1989), 853. 